\title{
Decision-making Processes for a Do-not-resuscitate Poisoned Pediatric Patient Admitted to the Department of Emergency and Medical Services - A Case Study
}

\author{
R. (III) P. DIOSO*
}

\begin{abstract}
A team of healthcare professionals in the Department of Emergency and Medical Services demonstrated decision-making processes for a poisoned pediatric patient with a Do-not-resuscitate (DNR) order. At the same time, clinical guidelines for poison resuscitations were critically applied. Lastly, the case examined and evaluated emergency care, management, treatment and diagnostic laboratory tests for pediatric poisoned patients.

Ideas on pertinent literatures of decision-making models, clinical guidelines on poison resuscitation and DNR policies were already known by the majority. In addition, ideas on the benefits such as becoming enlightened on how to make sound judgments in an emergency situation, particularly addressing issues on how to prioritize patients waiting in the emergency departments were featured.

Poison resuscitations were decided upon by using the descriptive, normative and prescriptive clinical decision-making models in a fast-paced environment. But the most important outcome however, was the recognition of client/relative satisfaction from hospital services - the demonstration of a sound decision-making that is legally, physiologically and financially in tandem with patient needs.
\end{abstract}

Key words: Clinical decision-making; poison; Department of Emergency and Medical Services; emergency; control

The case aims to apply the processes of decision-making to a Do-not-resuscitate (DNR) pediatric patient admitted to the Department of Emergency Medical Services (DEMS) of a state-run hospital located in a low-income country. It also aims to examine and evaluate the case of a 16-year-old female intoxicated pediatric patient to provide her with emergency care, management, diagnostic investigations and treatments. The descriptive, normative and prescriptive models of decision-making (Shaban 2005) are demonstrated and therefore concludes with a sound decision.
Ethics of justice were considered and this case study maintained anonymity of patients, healthcare professionals and hospital's name. The purpose is to make a world view on how a sound decision-making is demonstrated in a fast-paced environment.

\section{BACKGROUND OF THE STUDY}

The state-run hospital used for this study admits more than 180000 patients per year with over $1000+$ bed capacity - admitting an estimated $500+$ patients per day (Philippine Statistical

Lincoln University College Malaysia, Block A Lot 1, Mayang Plaza, 1 Jalan SS 26/1, Taman Mayang Jaya, 47301 Petaling Jaya, selangor, Malaysia

* Corresponding author (e-mail: duke@lincoln.edu.my) 
System, 2005). This is why the emergency department imposes a policy of 24-hours maximum waiting time as a driving force to ensure that all healthcare professionals work efficiently and effectively.

According to the Department of Health (DOH) (2005a), the issue on patient waiting time has become a worldwide problem. Due to the fact that in most countries the finances of patients are limited, thus it affects the hospitals' system of prioritizing those who needs immediate admission with free healthcare services (Sachs 2012; Kobusingye et al. 2005).

In addition, child protection and rights to have access to immediate treatment affects decisions on rationing hospital resources especially if the child's prognosis of surviving is poor, i.e. children who are comatose for two days due to poisoning requiring a free-of-charge use of mechanical ventilation (Lowry 2008; Aggarwal et al. 2004).

Incidence of child poisoning according to the World Health Organization (WHO) in 2004, are found on regions from Africa (4: 100 000), America (0.3:100 000), Southeast Asia (1.7:100 000), Europe (2:100 000), Eastern Mediterranean (1.6:100 000) and Western Pacific (1.8:100 000) per 100000 population. Table 1 shows the incidence of fatal child poisoning rates by using regions' and countries' income level.

\section{The Case}

A 16-year-old 50 kilogram female patient was admitted to the DEMS diagnosed with non- accidental, self-induced poisoning. According to the DEM guideline, a pediatric poisoning is always classified as emergent.

A statement taken from patient's relatives by the duty nurse at the DEMS triage admission desk showed that the patient took a liquid poison while alone at home in an apparent suicidal attempt. Baseline demographic data such as financial status or indigence were gathered by the social workers and documented it on the patient's record. Since the patient was indigent, being classified as belonging to a 'low income family', the hospital allowed her with a privilege to avail of free medical services (DOH 2005a).

The demographic data was documented and the consent from the relatives for patient's immediate care was secured.

WHO (2008) reiterates the importance of explaining procedures to relatives for emergency cases especially on pediatric patients ages 17 and below. Therefore, poison resuscitations were explained (Tables 3 and 4) before transferring her to the acute care unit.

\section{Upon Transfer to the Acute Care Unit}

An initial stabilization of circulation, airway and breathing was initiated by primarily connecting her to a cardiac monitor. It was then found that the patient's heart rate was 50 beats per minute and respiration was shallow; therefore the nurse-in-charge provided oxygen on facemask at high flow level to stabilize her oxygen circulation. In addition, an immediate assessment using a Glasgow coma scaling device was advised in order to monitor her

Table 1. Incidence of child poisoning on middle- and low-income regions and countries per 100000 population.

\begin{tabular}{cccccc}
\hline Africa & America & Southeast Asia & Europe & Eastern Mediterranean & Western Pacific \\
4 & 0.3 & 1.7 & 2 & 1.6 & 1.8 \\
\hline
\end{tabular}


level of consciousness (Stewart-Amidei 2009), found to be decreasing - a guideline from the American Heart Association (AHA) (2000/2010).

In response to the decreasing level of consciousness, an initial venous and arterial blood were extracted for investigations, which include sugars, creatinine, urea, electrolytes, hemoglobin, hematocrit, platelets, white blood cells and blood gases to investigate why the heart rate was decreasing and the breathing was shallow.

By intuition, charcoal resuscitation was then explained to the relatives by the team of healthcare professionals and gave out a written English pamphlet to give them a clear mental

Table 2. Written pamphlet used by clinical experts to explain the use of charcoal.

Position statement of single-dose and multiple-dose activated charcoal

Single-dose Activated Charcoal

- Sodium sulphate, sodium chloride and soap suds enema are used to avoid adverse reaction of charcoal resuscitation. This will reduce the incidence of bowel obstruction;

- Benefit from activated charcoal is more likely to occur if administered within one hour;

- There is the potential for some benefit to reduce morbidity and mortality of activated charcoal if administered after one hour of ingestion;

- The optimal dose is unknown but recommended to benefit: Babies up to 1 year of age: $10-25$ gram or $0.5-1.0$ gram/kilogram - Children 2 to 17 years of age: $25-50$ grams or $0.5-1.0$ gram/kilogram -Adolescents and adults: 25-100 grams;

- Activated charcoal has no benefits if the patient has an unprotected airway, if its use increases the risk of aspiration;

- The most common complication of activated charcoal is aspiration or direct instillation of activated charcoal into the lungs; and

- Activated charcoal may not benefit for some ingestants, including heavy metals, metal salts (lithium and iron), alcohols, cyanide and other rapid-acting medications.

Multiple-dose Activated Charcoal

- There are benefits demonstrating that multiple-dose activated charcoal reduces morbidity and mortality in the poisoned patient better than single-dose activated charcoal;

- Sodium sulphate, sodium chloride and soap suds enema are used to avoid adverse reaction of charcoal resuscitation. This will reduce the incidence of bowel obstruction;

- Multiple-dose activated charcoal benefits life-threatening ingestions of carbamazepine, dapsone, phenobarbital, quinine, theophylline, chlorox and alcohol;

- The first dose is recommended to benefit: Babies up to 1 year of age: 10-25 gram or 0.5-1.0 gram/ kilogram - Children 2 to 17 years of age: $25-50$ grams or $0.5-1.0$ gram $/ \mathrm{kg}$ - Adolescents and adults: $25-100$ grams and given every 8 hours interval;

- Multiple-dose activated charcoal is contraindicated if the patient has an unprotected airway, if its use increases the risk of aspiration or if any anatomical or medical conditions exist that may compromise by its benefits; and

- Rarely, aspiration, constipation and bowel obstruction can occur. 
picture of the planned resuscitation process.

Table 2 enumerates written position statements for single-dose and multiple-dose activated charcoal in a form of pamphlet.

When no bowel sounds were heard after auscultation of the abdomen of the patient, a nasogastric tube (size French 12), was then inserted to the patient and a nothing by mouth was ordered by the physicians in the DEMS in order to start the charcoal resuscitation.

The nurse-in-charge gave a single-dose of charcoal resuscitation followed by an insertion

Table 3. Clinical features and associated poisons.

(Lowry 2008; Weerasuriya et al. 2012; Aggarwal et al. 2004)

\begin{tabular}{|c|c|}
\hline Clinical features & Associated poisons \\
\hline Non-reactive pupils & $\begin{array}{l}\text { Chloroform, alcohol, cyanide, arsenic, organophosphates, } \\
\text { carbamates, phosphorus and kerosene. }\end{array}$ \\
\hline Odour of the breath & $\begin{array}{l}\text { Chloroform, alcohol, digitalis, cyanide, arsenic, organophosphates, } \\
\text { phosphorus and kerosene. }\end{array}$ \\
\hline Hypertension & Amphetamine, cocaine, and antipsychotic (mao inhibitor). \\
\hline Tachycardia & $\begin{array}{l}\text { Marijuana, phencyclidine, alcohol, nicotine, antihistamine, } \\
\text { antipsychotic, and antidepressant. }\end{array}$ \\
\hline $\begin{array}{l}\text { Hypotension, bradypnoea } \\
\text { and bradycardia }\end{array}$ & $\begin{array}{l}\text { Antidepressants (severe cases), barbiturates, narcotics, } \\
\text { benzodiazepines, cyanides, nicotinics, organophosphates, } \\
\text { alcohols and chloroforms. }\end{array}$ \\
\hline Hypotension and tachycardia & $\begin{array}{l}\text { Aluminium phosphides, antipsychotics, caffeines, cyanides, } \\
\text { disulphiram-ethanols, and tricyclic antidepressants. }\end{array}$ \\
\hline Hyperthermia & $\begin{array}{l}\text { Amoxapines, amphetamines, antidepressants, cocaines, lithiums, } \\
\text { phencyclidines, anticholinergics, salicylates and antihistamines. }\end{array}$ \\
\hline Hypothermia & $\begin{array}{l}\text { Antidepressants, ethanols, benzodiazepines, narcotics, barbiturates, } \\
\text { phenothiazines, alcohols and chloroforms. }\end{array}$ \\
\hline $\begin{array}{l}\text { Tachypnoea and respiratory } \\
\text { acidosis }\end{array}$ & $\begin{array}{l}\text { Amphetamines, atropines, cocaines, salicylates, carbon monoxides, } \\
\text { cyanides, paracetamols and amatoxin mushrooms. }\end{array}$ \\
\hline $\begin{array}{l}\text { Bradypnea, loss of bowel sounds } \\
\text { and metabolic alkalosis }\end{array}$ & $\begin{array}{l}\text { Antidepressants, antipsychotic agents, barbiturates, ethanols, } \\
\text { benzodiazepines, chlorinated hydrocarbons, narcotics, } \\
\text { nicotines, organophosphates, cobra salivas, antidepressants, } \\
\text { antihistamines, organophosphates, barbiturates, lithiums, } \\
\text { cyanides, narcotics and carbon monoxides }\end{array}$ \\
\hline Seizures & $\begin{array}{l}\text { Antidepressants (amoxapine and maprotiline), antipsychotics, } \\
\text { antihistamines, chlorinated hydrocarbons, organophosphates, } \\
\text { cyanide, leads and other heavy metals, lithiums, narcotics, } \\
\text { sympathomimetics }\end{array}$ \\
\hline Meiosis (Constricted pupils) & $\begin{array}{l}\text { Barbiturates, phenothiazines, ethanols, narcotics, nicotines, } \\
\text { organophosphates, chlorinated hydrocarbons, narcotics, and } \\
\text { cobra salivas }\end{array}$ \\
\hline Mydriasis (Dilated pupils) & $\begin{array}{l}\text { Amphetamines, caffeine, cocaines, nicotines, antidepressants, } \\
\text { antihistamines, atropines, methaemoglobinaemias, alcohols } \\
\text { and chloroforms }\end{array}$ \\
\hline
\end{tabular}


of continuous bladder drainage and taken urine samples for the presence of metabolites (Weerasuriya et al. 2012).

As a standard procedure, after charcoal resuscitation, the patient was placed on hourly monitoring to assess clinical features associated with poisons (Table 3).

Healthcare professionals involved in the care, management and treatment of the patient were guided by the active and passive complementary steps in resuscitation for poisoned patients (Table 4).

Table 4 highlights the algorithm or guideline on poison resuscitation that is according to the WHO (2008), to be always available on emergency departments worldwide.

Few hours passed, the nurse-in-charge for the patient noticed that she was having episodes of difficulties in breathing with blood oxygen level of $70 \%$. Immediately, the DEMS' physician-in-charge in the acute care unit intubated the patient with an endotracheal tube (size 6.5) as a form of active resuscitation in response to a decreasing blood oxygen level.

After intubation, the patient was connected to a mechanical ventilator by the physicianin-charge, to replace the facemask removed. Mechanical ventilator's settings were done according to patient's 50 kilogram weight

Table 4. Five complementary steps on both active and passive resuscitation for poisoned patients in the emergency department.

(AHA 2000; Aggarwal et al. 2004; WHO 2008)

\begin{tabular}{|c|c|}
\hline Steps & Activities as clinical guidelines \\
\hline Step 1: Initial stabilisation & $\begin{array}{l}\text { - On arrival of a patient with poisoning, the initial priorities are the } \\
\text { maintenance of circulation, airway and breathing whether it is in an } \\
\text { emergent or urgent case. } \\
\text { - If the patient has an altered level of consciousness, it is considered } \\
\text { to be in the category of emergent. Another emergent resuscitation is } \\
\text { intravenous fluid fast drip due to fluids loss. } \\
\text { - Before infusing intravenous fluids, blood should be withdrawn for } \\
\text { investigations, which include sugars, ureas, electrolytes and arterial } \\
\text { blood gases. }\end{array}$ \\
\hline $\begin{array}{l}\text { Step 2: Diagnosis of type } \\
\text { of poison }\end{array}$ & $\begin{array}{l}\text { - For a non-emergent or non-urgent category, this step can be done first } \\
\text { to complement with step } 1 \text {. This is also known as hourly monitoring. }\end{array}$ \\
\hline Step 3: Nonspecific therapy & $\begin{array}{l}\text { - The activities done here are the gastric lavage; gastric emptying, } \\
\text { enhancing fecal excretion, urine output manipulation, bowel irrigation } \\
\text { and use of activated charcoal after nasogastric tube insertion. }\end{array}$ \\
\hline Step 4: Specific therapy & $\begin{array}{l}\text { - Urine output manipulation. } \\
\text { - Mechanical ventilation or oxygen therapy. } \\
\text { - Cardioversion or defibrillation. }\end{array}$ \\
\hline Step 5: Supportive therapy & $\begin{array}{l}\text { - Antidotes are largely used for passive resuscitation. The aim is to } \\
\text { preserve the vital organ functions until poison is eliminated from } \\
\text { the body and the patient resumes normal physiological functions. }\end{array}$ \\
\hline
\end{tabular}


having her tidal volume (500 milliliters of air), required fraction of inspired oxygen $(100 \%)$, documented respiratory rate per minute $(20$ breaths per minute) and positive end expiratory pressure of $5 \mathrm{~cm}$ water, that was based on the guidelines for poisoned patients (AHA 2000).

When the patient's abnormal heart rhythm persisted, as shown on the heart monitor while on mechanical ventilation, healthcare professionals then referred the patient to the DEMS physician-in-charge for a choice of defibrillation or cardioversion as a form of active resuscitation (AHA 2010) in response to a premature ventricular contraction.

In response to an abnormal heart rhythm and hypotension the patient was then referred (Mace et al. 2008) to the toxicologist of the DEMS. She was then given an intravenous fluid for fluid resuscitation as ordered, in response to a low blood pressure.

As the patient's pupils became nonreactive, an antidote was given (AHA 2000) by the DEMS physician before referred to the Intensive Care Unit (ICU) for admission. However, there were no vacancies specifically for indigent patients as for the moment; therefore, the patient had to wait at the DEMS until further vacancies in ICUs were endorsed to the nurse-in-charge.

Hours, passed, an arterial blood gas result of the patient was interpreted by the DEMS physician and was noted to be a respiratory acidosis. In response to the arterial blood gas findings, the patient was positioned to moderate high back rest.

At the end of the 8-hour shift, the nursein-charge of the patient gave a report to the attending nurse in the succeeding shift for continuity of care and for further treatment and management. The endorsement of the patient's transfer to ICU was discussed by the team of nurses since it is more often a $90 \%$ chance of survival compared to a regular ward transfer which is $10 \%$ being practiced for intoxicated/ poisoned patients with unstable vital signs.

\section{After 24 Hours}

Hours passed but the patient did not improve from her comatose status, without spontaneous respiration. Her previous $70 \%$ partial oxygenation result after giving active and passive form of resuscitation was complicated by a loss of bowel sound and abnormal heart rhythm.

Again, a 70\% partial blood oxygenation result was recorded but with an improved pupilary reaction that sluggishly reacts to light. The non-spontaneous eye movement on Glasgow coma scale instigated the experts on poison control to respond by placing the patient on seizure precaution with body temperature monitoring every hour that may mask seizure episodes if chills occur (AHA 2000).

A second arterial blood gas assessment of the patient in response to a respiratory acidosis was again ordered. The result changed to a metabolic alkalosis (decrease in bicarbonate arterial blood level). A bicarbonate 50 MEQs drug was given intravenously by the DEMS physicians as one time dose (AHA 2010) in response to a metabolic alkalosis result.

Clinical experts provided rigorous resuscitation with antidotes, such as pralidoxime and Atropine in response to an unimproved heart rhythm noted through cardiac monitor.

The patient was given 1 litre of normal saline solution intravenously in response to low urine output noted every hour for 24 hours. Table 5 summarizes the care plan while the drug study was further explained in the Appendix. 


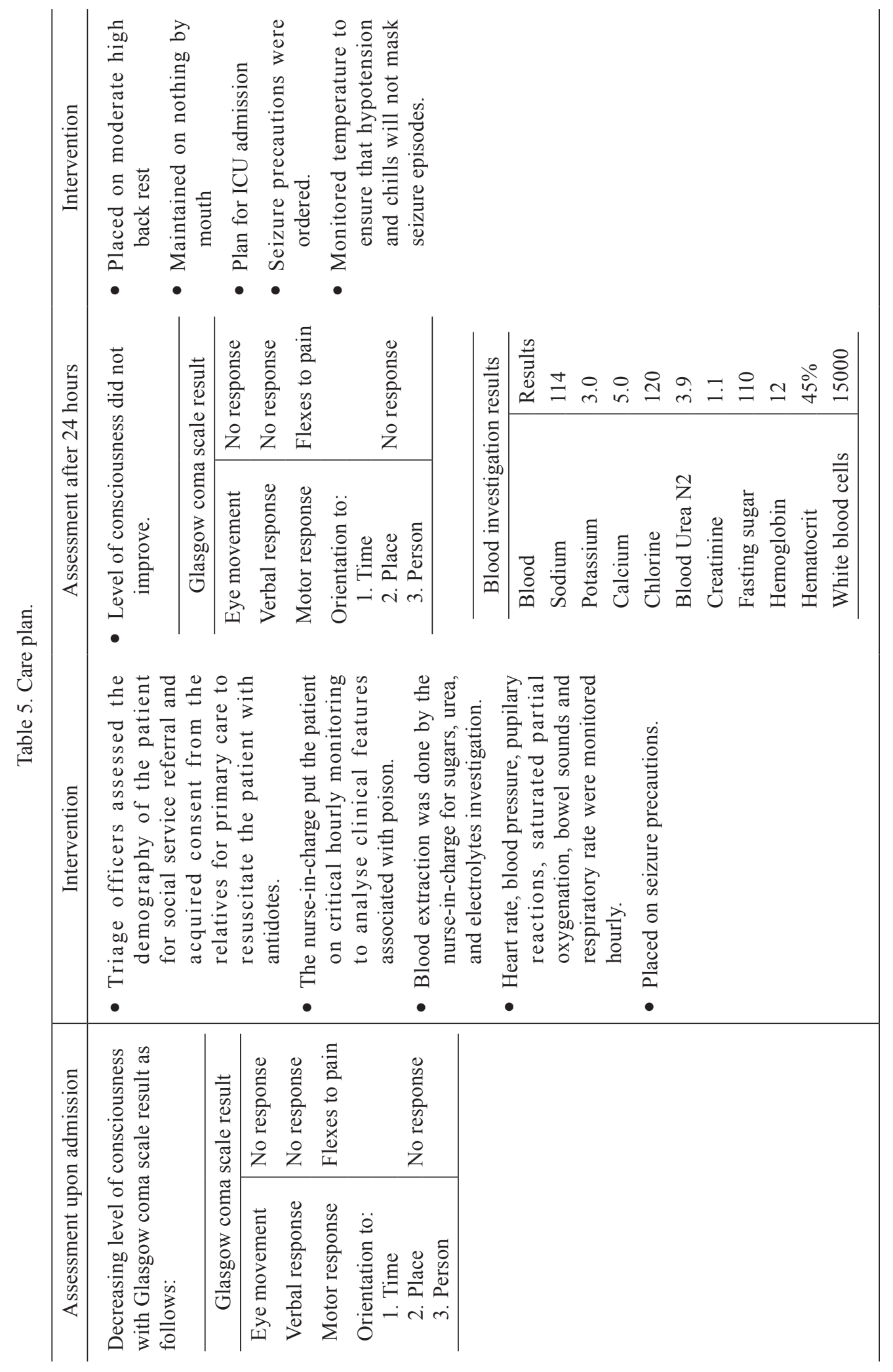




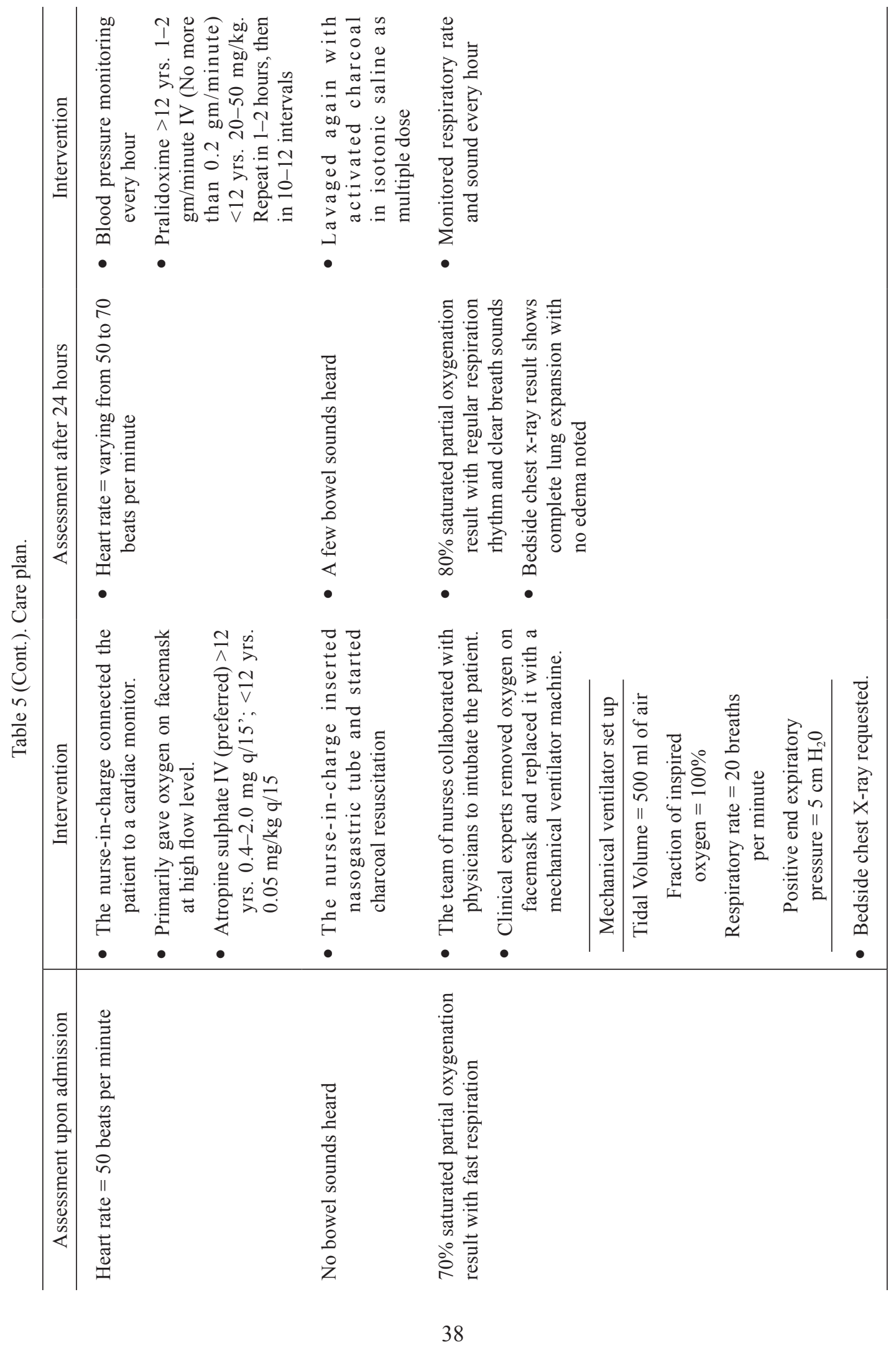




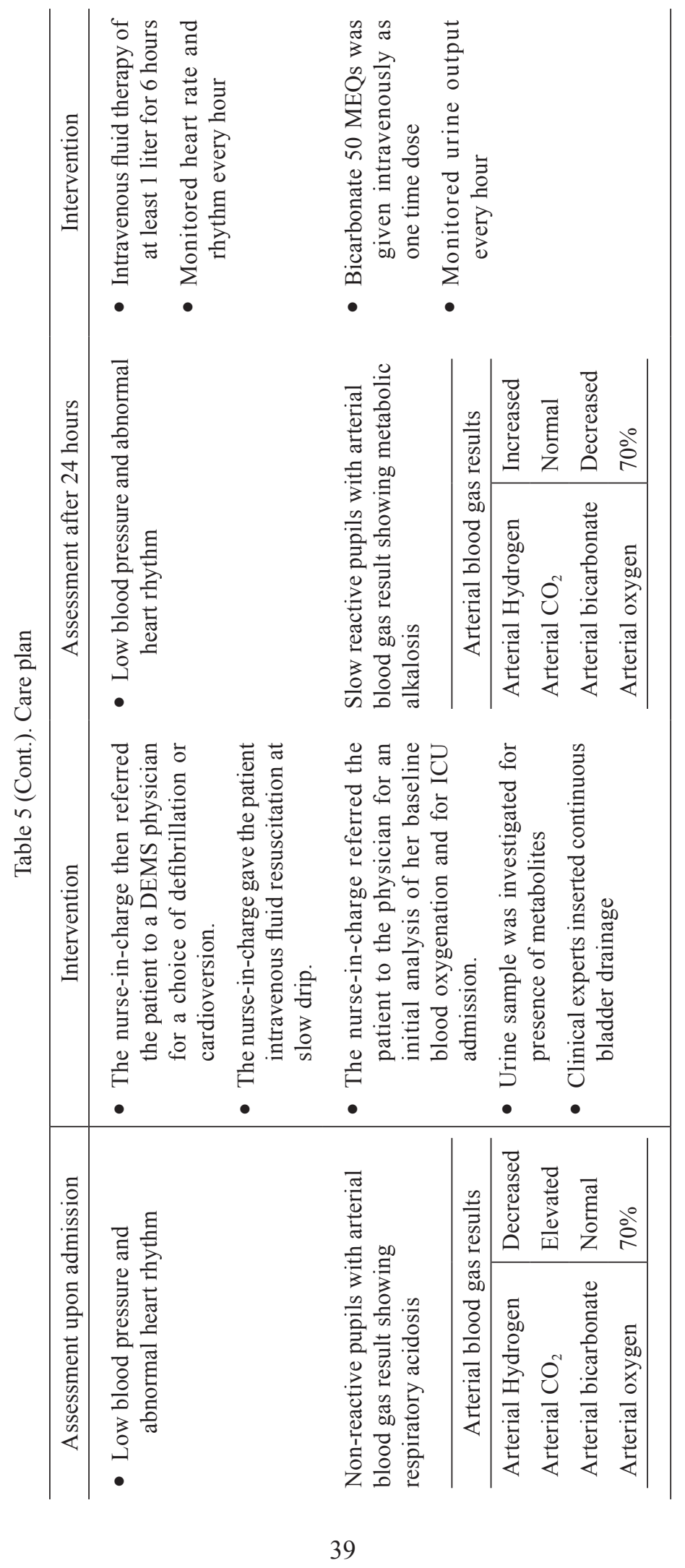




\section{After 72 Hours}

The condition of the patient prompted the attending physician to recommend DNR to the relatives and to the nurses-in-charge. A discussion was however made by the physician with the relatives whether to admit the patient who has been waiting in the DEMS for 48 hours or proceed with the signing of DNR consent to be effective immediately.

Probabilities were presented to the relatives during the discussion using the home against advice method (50\% practised), omission of medical treatment while confined in the hospital (5\% practised) and the provision of passive resuscitation without active resuscitation (45\% practised) in the acute care division of the DEMS. Relatives' decision (Say \& Thomson 2003) are also important to be considered. Figure 1 illustrates the decision tree divided into percentages recommendable for the pediatric indigent patient.

The DNR consent was signed. The poisoned DNR pediatric overstaying patient was restrained from receiving active resuscitation that is $45 \%$ practiced in clinical settings (WHO 2008). Clinical experts however, still intuitively recommended to the team of healthcare professionals that the indigent overstaying DNR pediatric patient should be monitored intensively in the acute care division of the DEMS department despite of her DNR status.

While the patient was being hourly monitored with all the assessment cues directly linked to poison clinical features, it was noticed by healthcare professionals, that the heart rate, heart rhythm and level of consciousness were accelerating and evidence of defecation was seen.

At early 72 hours in the DEMS, the overstaying DNR pediatric patient's Glasgow coma scale result $(9 / 15)$ improved. The poison was excreted out from her body as evidence by her bowel movement and urine output (Youngner et al. 1985; Aggarwal et al. 2004).

On her late 72nd hour in the DEMS, the patient was referred back to the physician by healthcare professionals to cancel the DNR decision and proceed with the plan of admitting the patient to the ICU using the social service for pediatrics for financial support.

However, in order to determine the diagnosed nicotinic effects of organophosphates and carbamates poisoning the blood levels of the patient, pralidoxime was again administered intravenously as one time dose (AHA 2000; Aggarwal et al. 2004) by the nurse-in-charge.

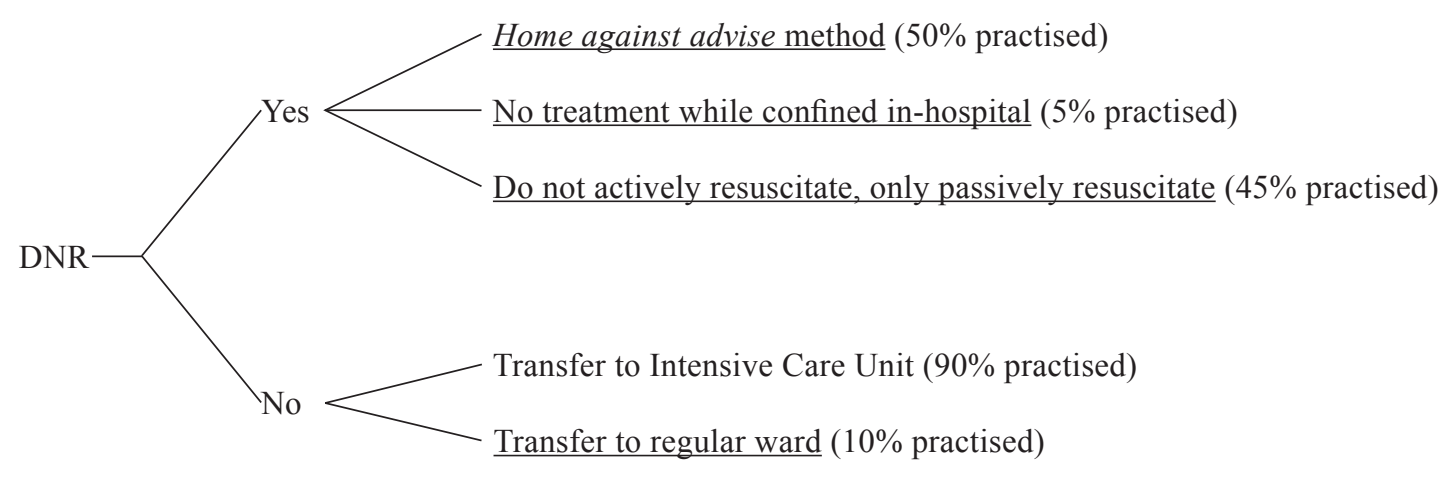

Figure 1. The decision tree divided into probabilities. 
This will bind and cleave phosphate-esters between organophosphates ingested as poison by the patient to its acetylcholinesterase thus detoxifies her completely (AHA 2000; Aggarwal et al. 2004; WHO 2008).

Figure 2 explains the pathophysiology of the disease process analyzed on the patient's case and discusses how hidden signs and symptoms occurred termed as the pseudoallergic reactions.

\section{METHODOLOGY}

This section examines and evaluates how the three basic models of decision-making — the descriptive, prescriptive and normative - were applied.

A descriptive decision is characterized by understanding how individuals make judgments and decisions focusing on the actual conditions, contexts, ecologies and environments in which they are made (Shaban 2005). An advantage of the descriptive model is the adequacy in supporting assumptions made about decisionmaking processes with relevant examples from a suitable period of observation (Shaban 2005). An example is intuition (Offredy \& Meerabeau 2005; Bell et al. 1995).

Normative models in decision-making process (Offredy 1998; Shaban 2005) are characterized by rational, logical and scientific procedures supported by clear or probable evidences (Harrison 1996). Statistical analyses with decision trees of large-scale experimental and survey research which is representative of a target population where the findings apply are information sources in a normative decision (Bell et al. 1995). Advantages herewith enable decision-makers to predict and explain the outcomes of decisions and minimize judgment errors (Thompson \& Dowding 2002) especially when patients or relatives are key decision makers (Say \& Thomson 2003).
Lastly, prescriptive models use information processing theory as a prescriptive tool to assist practitioners in enhancing decision tasks to analyse sources, principles and findings of previous research or clinical guidelines with algorithms (Shaban 2005).

Table 6 summarizes the three decisionmaking models.

\section{The Prescriptive Decision-making: Information Processing Theory Applied}

Its characteristic uses framework or information and facilitating more effective decisionmaking as its advantage (Bell et al. 1995).

\section{Information Processing Theory Step One: Cue Acquisition}

Using clinical guidelines the cues were acquired. Biophysiologic instruments used to acquire cues were the Glasgow coma scale, electrocardiograms, pulse oxymeter, urine collection, blood pressure auscultation, and venous and arterial blood interpreting machines (Stewar-Amidei 2009; AHA 2010). Other important cues acquired are her pupilary reactions, urine outputs, and bowel sounds (Mace et al. 2008; AHA 2000) to support the cues investigated through biophysiologic instrumentations.

\section{Information Processing Theory Step Two: Hypothesis Generation}

Healthcare professionals caring, treating and managing the poisoned pediatric patient hypothesized that she has ingested organophosphate and carbamate poisons found in insecticides. It was also hypothesized by the clinical experts that the patient had a prolonged paralysis of the muscles such as the diaphragm and heart. Therefore, clinical experts hypothesized that she needs to be monitored her intensively. 

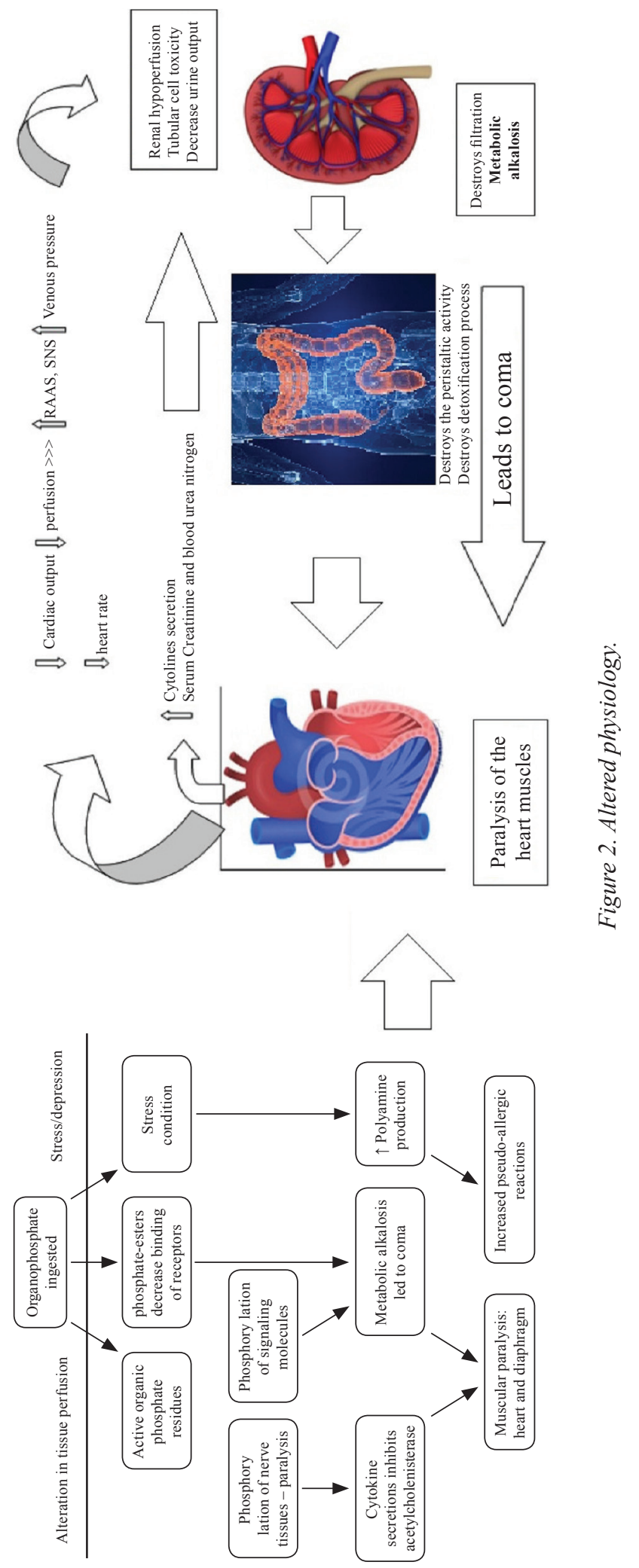
Table 6. Summary of three decision-making models.

(Shaban 2005; Thompson \& Dowding, 2002; Tanner et al. 1987; Offredy 1998)

\begin{tabular}{|c|c|}
\hline \multicolumn{2}{|r|}{ Normative model } \\
\hline Characteristics & Rational, logical, scientific, evidence based decisions. \\
\hline Information sources & $\begin{array}{l}\text { Statistical analysis of large-scale experimental and survey research which is } \\
\text { representative of a target population where the findings can be applied. }\end{array}$ \\
\hline Examples & Decision trees. \\
\hline Advantages & Enable decision-makers to predict and explain the outcomes of decisions. \\
\hline \multicolumn{2}{|r|}{ Prescriptive model } \\
\hline Characteristics & $\begin{array}{l}\text { Frameworks or information processing designed to enhance specific decision } \\
\text { tasks. }\end{array}$ \\
\hline Information sources & $\begin{array}{l}\text { Principles and findings of previous scientific research (associated with } \\
\text { normative models). }\end{array}$ \\
\hline Examples & $\begin{array}{l}\text { Cue acquisition, hypothesis generation, interpretation of cues, and hypothesis } \\
\text { generation - information processing theory. }\end{array}$ \\
\hline Advantage & Facilitating more effective decision-making. \\
\hline \multicolumn{2}{|r|}{ Descriptive model } \\
\hline Characteristics & $\begin{array}{l}\text { Understanding how individuals make judgments and decisions focusing on } \\
\text { the actual conditions, contexts, ecologies, and environments in which they } \\
\text { are made. }\end{array}$ \\
\hline Information sources & Observation, description and analysis \\
\hline Examples & "Think Aloud", humanistic intuition and pattern recognition \\
\hline Advantage & $\begin{array}{l}\text { Adequacy in supporting assumptions made about decision-making processes } \\
\text { with relevant examples from a suitable period of observation. }\end{array}$ \\
\hline
\end{tabular}

As the patient prognosis of survival did not improve after 24 hours the DEMS physicians hypothesized that a DNR should be recommended to the relatives.

\section{Information Processing Theory Step Three: Interpretation of Cues}

The patient was interpreted to be experiencing muscular paralysis — including the diaphragm and heart muscles - due to the manifested slow and shallow breathing and hypotension. In addition, it was also interpreted that the acetylcholinesterase was destroyed, hence the neurotransmitter called acetylcholine could not be broken down or deactivated leading to an over stimulation of the parasympathetic nervous system. The results were both muscarinic and nicotinic effects. That is why she was given treatments such as atropine and pralidoxime while activated charcoals were given via nasogastric tube as antidotes (refer to Appendix 1).

\section{Information Processing Theory Step Four: Hypothesis Evaluation}

In this step, DEMS physicians (especially the poison specialists) caring, treating and managing the patient recommended DNR. This was due to the deteriorating condition of the patient during the first 24 hours from 
admission. In addition to this specific hospital's local policy of 24-hour overstay for patients in the DEMS, a slow reactive pupil for 48 hours was evaluated to be insufficient to recommend a free medical service usually granted by the hospital insurance agency.

\section{The Normative Decision-making: Decision Trees}

Patients' relatives were presented with options in a form of decision trees (Say \& Thomson 2003). The decision tree found on Figure 1 was used for this case based on the clinical guidelines in outlining options. However, the physicians still instigated that DNR be advised because the prescriptive decision-making process was the norm that is always done in the DEMS.

\section{Descriptive Decision Making: Intuition}

Intuitively, during the first 24 hours in the acute care unit of the DEMS, the collaborating healthcare professionals descriptively decided that the patient could be placed in the ICU due to a recognized pattern of complex masked assessment cues or hidden signs and symptoms (Phaneuf 2008) from poisoned patients undergoing active resuscitation.

In a descriptive decision-making, intuition (Offredy \& Meerabeau 2005) enumerates probabilities during a discussion. Probabilities are easier to use when collaborating with other experts to intuitively enumerate tasks to measure clinical reasoning (McAllister et al. 2009). In addition to Brien and coresearcher's (2011) and Benner and Tanner's (1987) study on how to trust an intution, Hams (2000) also said that during discussions with the relatives and the clinical experts, patterns of previously experienced events must be intuitively considered in order to validate an intuition. Banning (2007) supported this method of decision-making as a role of learning from experiences.
Intuitions are done descriptively according to Banning (2007) by starting with an intuitive hypothesis and perception.

This links to the interpretation of cues from the information processing theory (Tanner et al. 1987) of the prescriptive model, that the patient is manifesting hidden signs and symptoms also known as complex masked assessment cues (Phaneuf 2008; Stewart-Amidei 2009).

Thereby DNR was chosen at an early stage of consultation (after 24 hours) but was rejected at the late 72 hours of the patient in the DEMS.

It is usually during the late stage of consultation where intuitive hypothesis generation is trusted. That is why the patient was decided to be admitted to the ICU after 72 hours.

Banning (2007) said that this process of decision-making, as an intuitive perception is also done by recognizing patterns from past experiences. Figure 3 shows the process of trusting an intuition.

\section{DISCUSSION}

This section discusses the policy on DNR and the analysis on poison control as a clinical guideline that affects the decision-making.

\section{The Poison Control Guideline Affecting the Decision-making}

Poison control guideline affects decisionmaking in providing a more effective resuscitation especially in a fast-paced environment (Lowry 2008; Bronstein et al. 2006). Clinical features of poisoned victims can be delayed, which is also known as complex masked assessment cues or hidden signs and symptoms, hence decision-making must not be in a rush and done with good clinical judgment (Phaneuf 2008). 


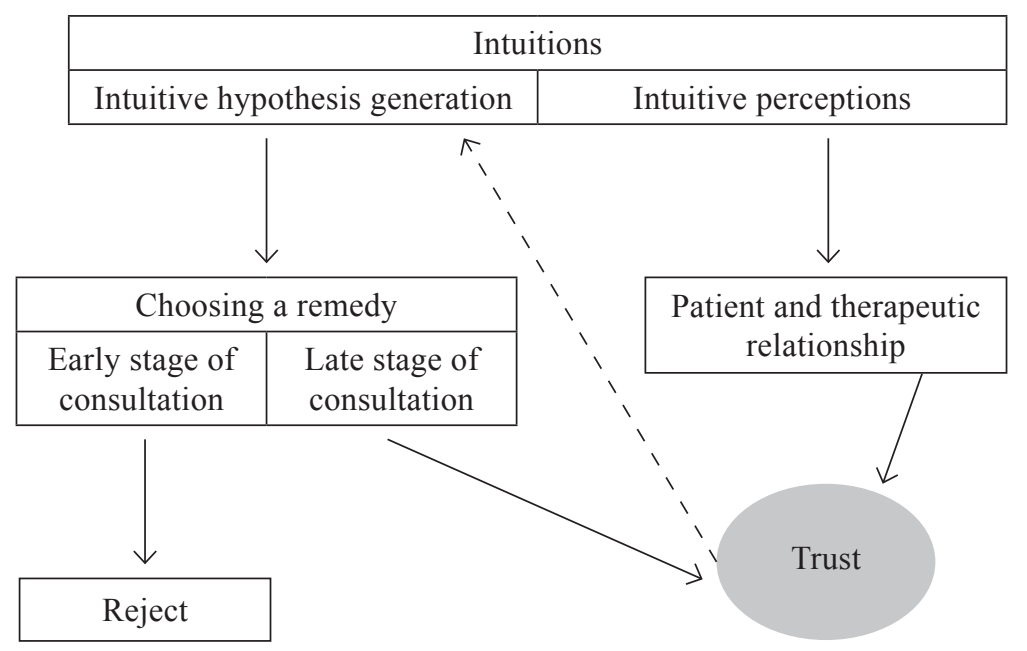

Figure 3. How to use an intuition.

There is a potential for decision-makers to commit errors if poison control guidelines were not critically analyzed. It was also expected that healthcare professionals must neither be too prescriptive nor descriptive in receiving orders that are found on clinical guidelines since a sound decision-making should not be affected by such. On the contrary, it does affect decisionmaking especially in the emergency department where every healthcare professionals and clinical experts rushes to make decisions. That is why in a fast paced environment, decisionmaking must use all the three processes to avoid errors. Therefore, rushing a decision affects a sound decision-making.

According to AHA (2000) and Aggarwal et al. (2004), acute poisoning was a common medical emergency that needs intensive care, management and treatment that are expensive. This again affected decision-making. Clinical guidelines could help in rationing expensive resources such as mechanical ventilators, heart monitor, drug antidotes and catheters to patients. But instead, the poison clinical guideline was used in a fast-paced environment to control wasting expensive resources by not giving priority to indigent patients who could not afford to pay for the replenishments of such.
That was why relatives/significant others responsible for a comatose patient chooses DNR especially if they lacked funds and insurance agencies denied their application for financial support.

\section{The Policy on Do-not-resuscitate Affecting the Decision-making}

A DNR option affects decision-making of healthcare professionals to patients of minor age especially when consent was signed to initiate a passive form of euthanasia that was unsoundly decided upon by the relatives. This is the omission of certain kinds of medical care, management and treatment (DOH 2005a) which was approved by the United Nations during the 1960s (Tolentino 1973) and has been used in this specific hospital (5\% practised). Furthermore, research shows that most middleincome and low-income countries practise this system by omitting certain kinds of medical care that are used to sustain a patient's life (Kobusingye et al. 2005). This is the most common form of passive euthanasia (Tolentino 1973) - supported by a written consent (White 2010; Mace et al. 2008; Lin et al. 1999) voluntarily signed by either the patient or by the relatives/significant others. 
The act of discharging is another method of executing a DNR (DOH 2005a) affects decision-making because it is consented and signed by relatives/significant others taking responsibility to bring home their patient against medical advice. In addition, this is against the rules of medical ethics on a patient with an existing heartbeat (DOH 2005a). This policy includes a criteria that the patient should still be in the state of 'being alive' before being discharged (Tolentino 1973). This form of passive euthanasia is more often used in this hospital (50\% practised) and was formulated to 'avoid potential future litigation for negligence to treat when required' (Lin et al. 1999). Furthermore, it also affects the decision-making, because if the patient dies in the hospital after a discharge against medical advice is signed, negligence to treat maybe charged against healthcare professionals especially if a DNR decision is proven to be an error (DOH 2005a). Other research that supports the DNR local policy using the act of discharging says that death should occur outside hospital boundaries (Olsen et al. 1993). And according to the Philippine Nurses' Association (PNA) (1990), the patient must still be alive before she reaches her own home to give her a dignified death.

All these factors discussed affect the decision-making. There are three questions recommended for clinical decision-makers to consider who would in the future encounter the same or similar case.

\section{RECOMMENDATIONS}

(1) Was the relative's or others of significant whose preference of care, management and treatment considered and respected? This question was important to be asked because it addressed the financial barriers in decision-making thus, could affects the decision.
(2) Was the decision to have benefits could outweigh the harm? This question was also as important as with Question 1 since it addresses the impact of a decision in reality.

(3) How was the practise of autonomy in decision-making applied in this case? This question addressed the legal issues affecting the decision-making.

\section{The Financial Barrier in Decision-making - Addressing Question 1}

It was recommended that the clients' or relatives' or others significant, whose preference of treatment, care and management would be prioritized.

However, hospital policies in high- middleand low-income countries do not show equal distribution of free healthcare services and health insurances' assistance if the patient has poor prognosis of surviving (Taylor \& Xiaoyun 2012; Kobusingye et al. 2005).

It is indeed true, that the patients in public hospitals of middle- and low-income countries who are below poverty line (Pagaduan-Lopez 1991) experiences similar situations among patients on high-income countries (Sachs 2012). Providing free health services is government's perennial problem on, high-, middle, and lowincome countries (Ranson \& Bennett 2009; Chen \& Lit 2003; DOH 2005a). Hospitalization is expensive. Rentals for mechanical ventilators in the ICU are even more expensive (Reeves 1997).

The lesser the chances of survival connote the lesser the priority for accessing free healthcare services (Kobusingye et al. 2005). This financial need pushes relatives or significant others of indigent patients in government hospitals to make preferences based on their available funds (Lin et al. 1999; 
Chen \& Lit 2003). This financial problem also makes autonomous decision-makers - the relatives and significant others — to push themselves to the less expensive form of care, management and treatment, or sometimes agree with DNR (PNA 1990; Reeves 1997).

Nevertheless, it is recommended that the final decision or preference would still come from the client or relatives/others who were significant (whether manipulated or not).

\section{The Impact of Beneficence Versus Non- malefesance on the reality of decision- making - Addressing Question 2}

It was recommended that somehow, physicians could not prematurely recommend DNR especially when urgency of the situation in a fast paced environment deemed it necessary.

However, on government-owned hospitals in middle-, high- or low-income countries, for the benefit of the hospital that lacks bed capacity it is recommended to find ways on how to prioritize admissible patients that will somehow regain the quality of life (Kobusingye et al. 2005; DOH 2005b). While some physicians discuss DNR decision prematurely in a fastpaced environment such as the DEMS, it was seen as beneficial for others who also needed to be admitted. A DNR order is a reality that is always done in the DEMS (Weerasuriya et al. 2012). The benefit of prematurely deciding to send the patient home with poor prognosis of survival offered an advantage to other patients who were waiting to be admitted and had more chances of surviving.

While it is recommended to send patients home because of limited bed capacity, there is however a debatable reality impacting children's rights to be prioritized for hospital admissions whether they have a poor prognosis of surviving (Bass 2003; De Gendt et al. 2007; Miles \& Burke 1996).

\section{The Legal Issues Affecting Autonomy in Decision-making - Addressing Question 3}

As highlighted by the National Consent Advisory Group (NCAG) (2012), it is recommended that children who are minors aged 12-years old to 17-years old must have the priority for access in most hospitals as a part of the universal child protection act. In support to this act, most senate health committee disapproves proposals of passive euthanasia for pediatrics (Pagaduan-Lopez 1991; Tolentino 1973) (Lin et al. 1999; Jevon 1999).

These legal issues are subject to affect an autonomous decision-maker who will be deemed to answer against the universal antimedical malpractice law (Jevon 1999; Lin et al. 1999). It is recommended that decision makers in the emergency must uphold this law because it values human life settings (NCAG 2012; McClain \& Perkins 2002).

\section{CONCLUSION}

It was therefore concluded that in this case study, information processing theory recommended DNR. Secondly, decision trees with options that affected the DNR decision had considered probabilities of patient survival. That is why intuition had made an impact on the decisionmaking process on this case that the patient was only experiencing complex masked assessment cues or hidden signs and symptoms, so the DNR decision was cancelled.

This case did not directly suggest the use of intuition, but concluded that decision-making on the DEMS started with critical awareness of the local policies in tandem with clinical guidelines.

Humanistic intuition and pattern recognition in a CDM process may resolve complex problems such as lacking of funds (Harris \& Davies 2007), for indigent patients. 
But these intuitions required extreme caution such as the recognition of patterns of previously encountered similar events especially in an emergency context to avoid error in decisionmaking.

Information processing in this case study, on the other hand, limited perspectives to only one side of the problem using clinical guidelines or algorithms (Manias \& Street 2001). The decision was hence, detrimental to the patient. Therefore, in order to demonstrate a comprehensive range of sound judgment, the decision-maker must be in control emotionally, psychologically and intellectually (Lloyd et al. 2011) without rushing into a decision using clinical guidelines.

Problem solving using the normative decision-making in this case was somehow better if it was not affected primarily by clinical guidelines. This process used decision trees as options presented to patients and/or relatives significant to others. Broadening perspective using options was a key to decision-making. This system created a mental framework by cautiously considering all options, especially in a fast-paced environment, thereby turned decisions away from frame prescriptive blindness on algorithms and clinical guidelines.

Finally, deciding on patients' waiting time in the emergency departments worldwide also considers seeing the wider picture (Harris \& Davies 2007; Howard 2011) — the legal, economical and physiological issues using the decision-making processes. These considerations reflect sound decision-making if demonstrated well by their healthcare employees (Manias \& Street 2001). Therefore, by looking on all sides of the problem before plunging in to a decision, the results of customer/ client service satisfaction would be evident or effective enough to maintain a good image of a hospital and its healthcare employees.

Date of submission: March 2015

Date of acceptance: May 2015

\section{REFERENCES}

Aggarwal, P, Handa, R \& Wali, JP 2004, 'Acute poisoning - management guidelines', Journal of Indian Academy of Clinical Medicine, vol. 5, no. 2, pp. 142-147.

American Heart Association 2000, Part 8: Advanced challenges in resuscitation: section 2: toxicology in ECC, American Heart Association, Dallas.

American Heart Association 2010, Guidelines for cardio-pulmonary resuscitation and emergency cardiovascular care for healthcare providers, American Heart Association Press, Dallas.

Atwal, A \& Caldwell, K 2002, 'Do multidisciplinary integrated care pathways improve interprofessional collaboration?', Journal of Scandinavian Caring Sciences, vol. 16, no. 4, pp. 360-7.

Banning, M 2007, 'A review of clinical decision making: models and current research', Journal of Clinical Nursing, vol. 17, no. 2, pp. 187-195.

Bass, M 2003 'Oncology nurses' perceptions of their role in resuscitation decisions', Professional Nurse, vol. 18, no. 12, pp. 710-715.

Bell, DE, Raiffa, H \& Tversky, A 1995, 'Descriptive, normative and prescriptive interactions in decision making', eds. DE Bell, H Raiffa \& A Tversky in Decision-Making, Cambridge University Press, Cambridge.

Benner, P \& Tanner, C 1987, 'Clinical judgment: how expert nurses use intuition', American Journal of Nursing, vol. 87, pp. 23-31.

Brien, S, Bridget, D \& Burch, A 2011, 'The use of intuition in homeopathic clinical decision making: an interpretative phenomenological study', Evidence-Based Complementary and Alternative Medicine, vol. 1, pp. 1-8.

Bronstein, AC, Spyker, DA \& Cantilena, LR 2006, 'Annual Report of the American Association of Poison Control Centers' National Poison 
Data System', Clinical Toxicology, vol. 45, pp. 815-917.

Chen, PCY \& Lit, PK 2003, 'Equity in healthcare in developing countries', Malaysia: Journal Kesihatan Masyarakat.

Damiani, G, Pinnarelli, L, Colosimo, S, Almiento, R, Sicuro, L, Galasso, R, Sommella, L \& Ricciardi, W 2010, 'The effectiveness of computerized clinical guidelines in the process of care: a systematic review', BMC Health Service Research, vol. 10, no. 2 , pp. $1-11$.

De Gendt, C et al. 2007, 'Nurses' involvement in 'do not resuscitate' decisions on acute elder care wards', Journal of Advanced Nursing, vol. 57, no. 4, pp. 404-409.

Department of Health 2005a, Health Statistics. Manila: DOH. viewed October 2012, <www. DOH.gov.ph.>.

Department of Health 2005b, Health policies and laws, DOH: Manila, viewed October 2012, $<$ www.DOH.gov.ph.>.

Hams, SP 2000, 'A gut feeling? Intuition and critical care nursing', Intensive and Critical Care Nursing, vol. 16, no. 5, pp. 310-318.

Harris, D \& Davies, R 2007, 'An audit of 'do not attempt resuscitation' decisions in two district general hospitals: do current guidelines need changing?', Postgraduate Medical Journal, vol. 83, pp. 137-140.

Harrison, FE 1996, 'A process perspective on strategic decision making', Management Decision, vol. 34, no. 1, pp. 46-53.

Howard, PK 2011, 'Prioritizing patients with acuity 3', Journal of Emergency Nursing, vol. 37, no. 3, pp. 296-297.

Jevon, P 1999, 'Do not resuscitate orders: the issues', Nursing Standard, vol. 13, no. 40, pp. 45-46.

Kobusingye, O, Hyder, A, Bishai, D, Hicks, E, Mock, C \& Joshipura, M 2005, 'Emergency medical system in low and middle income countries: recommendations for action', Bulletin of the World Health Organization, vol. 83, no. 8, pp. 626-631.

Lin, JM, Lin, WC, Chen, Y., Wu, HW, Yao, NS, Chen, LT \& Whang-Peng, J 1999, 'The status of the do-not-resuscitate order in Chinese, clinical trial in a cancer center', Journal of Medical Ethics, vol. 25, pp. 309-314.

Lloyd, J, Schneider, J, Scales, K, Bailey, S \& Jones, R 2011, 'Ingroup identity as an obstacle to effective multiprofessional and interprofessional teamwork: findings from an ethnographic study of healthcare assistants in dementia care', Journal of Interprofessional Care, vol. 25, pp. 345-351.

Lowry, JA 2008, 'Use of activated charcoal in pediatric populations', in Second Meeting of the Subcommittee of the Expert Committee on the Selection and Use of Essential Medicines, The Children's Mercy Hospitals and Clinics, Division of Clinical Pharmacology, Geneva.

Mace, SE, Brown, LA, Francis, L, Godwin, SA, Hahn, SA, Howard, PK, Kennedy, RM, Mooney, DP, Sacchetti, AD, Wears, RL \& Clark, RM 2008, 'Clinical Policy: Critical issues in the sedation of pediatric patients in the Emergency Department', Journal of Emergency Medicine, vol. 34, no. 3, pp. e33-e107.

Manias, E \& Street, A 2001, 'The interplay of knowledge and decision making between nurses and doctors in critical care', International Journal of Nursing Studies, vol. 38, pp. 129-140.

McAllister, M, Billett, S, Moyle, W \& ZimmerGembeck, M 2009, 'Use of a think-aloud procedure to explore the relationship between clinical reasoning and solution-focused training in self-harm for emergency nurses', Journal of Psychiatric and Mental Health Nursing, vol. 16, pp. 121-128).

McClain, K \& Perkins, P 2002, 'Terminally ill patients in the Emergency Department: a practical review of end-of-life issues', Journal of Emergency Nursing, vol. 28, no. 6, pp. 515-522.

Miles, J \& Burke, L 1996, 'Nurses' views of the decision not to resuscitate a patient', Nursing Standard, vol. 10, pp. 33-38.

National Consent Advisory Group 2012, National consent policy. Part 4 of do not attempt resuscitation, Quarterly Public Sector Department, London.

Offredy \& Meerabeau 2005, "The use of "Think Aloud" technique, information processing theory and schema theory to explain decision-making processes of general practitioners and nurse 
practitioners using patient scenarios', Primary Healthcare Research and Development, vol. 6, pp. 46-59.

Offredy, M 1998, 'The application of decision making concepts by nurse practitioners in general practice', Journal of Advanced Nursing, vol. 28 no. 5, pp. 1-2.

Olsen, EB, Lowenstein, SR, Koziol-McLain, J \& Summers, JG 1993, 'Do-not-resuscitate order. What happens after hospital discharge?', Western Journal of Medicine, vol. 158, no. 5, pp. 484-487.

Pagaduan-Lopez, J 1991, 'Medico professionals and human rights in the Philippines', Journal of Medical Ethics, vol. 17, pp. 42-50.

Phaneuf, M 2008, Clinical judgement - an essential tool in the nursing profession, Resources in Nursing, Infiressources, France.

Philippine Nurses' Association 1990, Code of professional conduct for Philippine Registered Nurses, 2 edn, Professional Regulations Commission, Manila.

Philippine Statistical System 2005, Philippine National Statistical Coordination Board, National Statistics Office, Manila, viewed October, 2012, $<$ www.NSCB.gov.ph.>.

Ranson, MK, \& Bennett, SC 2009, 'Priority setting and health policy and systems research', Health Research Policy and Systems, vol. 7, no. 27, pp. $1-7)$.

Reeves, K 1997, 'Euthanasia, assisted suicide and the right to die', Journal of Emergency Nursing, vol. 23 , no. 5, pp. 393-394.

Sachs, JD 2012, 'Primary health care in low-income countries building on recent achievements', Journal of the American Medical Association, vol. 307, no. 19 pp. 2031-2032.

Say, R \& Thomson, R 2003, 'The importance of patient references in treatment decision challenges for doctors', British Medical Journal, vol. 327 , pp. 542-545.

Shaban, R 2005, 'Theories of clinical judgment and decision-making: a review of the theoretical literature', Journal of Emergency Primary Health Care, vol. 3, no. 1-2, pp. 1-10.

Stewart-Amidei, C 2009, Management of comatose or confused clients. Medical-surgical nursing, clinical management for positive outcomes, Saunders, Texas.

Tanner, C, Padrick, K, Westfall, U \& Putzier, D 1987, 'Diagnostic reasoning strategies for nurses and nursing students', Nursing Research, vol. 36, pp. 358-363.

Taylor, JG \& Xiaoyun, L 2012, 'China’s charging poverty: a middle income country case study', Journal of International Development, vol. 24, no. 6, pp. 700-709.

Thompson, C \& Dowding D 2002, Clinical decision making and judgment in nursing, Churchill Livingstone, London.

Tolentino, A 1973, Is there a right to die? A study of the law of euthanasia, University of the Philippines, University Press, Diliman.

Weber, S 2007, 'Clinical decision support systems and how critical care clinicians use them', Journal of Healthcare Information Management, vol. 21, no. 2, pp. 41-52.

Weerasuriya, D, Sheikh, S \& Morgan, BW 2012, 'Do not resuscitate orders in fatal toxic exposures: a poison center's review', Western Journal of Emergency Medicine, vol. 8, no. 3, pp. 294-297.

White, A 2010, 'An evidence based clinical guidelines for initial management of behavioral emergencies', Journal of Emergency Nursing, vol. 36 , no. 5 , pp. $450-454$.

World Health Organization 2004, World report on child injury prevention: children and poisoning, Library Cataloguing-in-Publication Data, Geneva Switzerland.

World Health Organization 2008, Manual for the health care of children in humanitarian emergencies, Library Cataloguing-in-Publication Data, Madrid, Spain.

Youngner, S, Lewandowski, W, McClish, D, Juknialis, B, Coulton, C \& Bartlett, E 1985, 'Do not resuscitate' orders incidence and implications in a medical intensive care unit', Journal of the American Medical Association, vol. 253, no. 1, pp. 54-57.

Yura, H \& Walsh, MB 1973 The nursing process: assessing, planning, implementing and evaluating, 2 edn, Appleton-Century-Crofts, New York. 


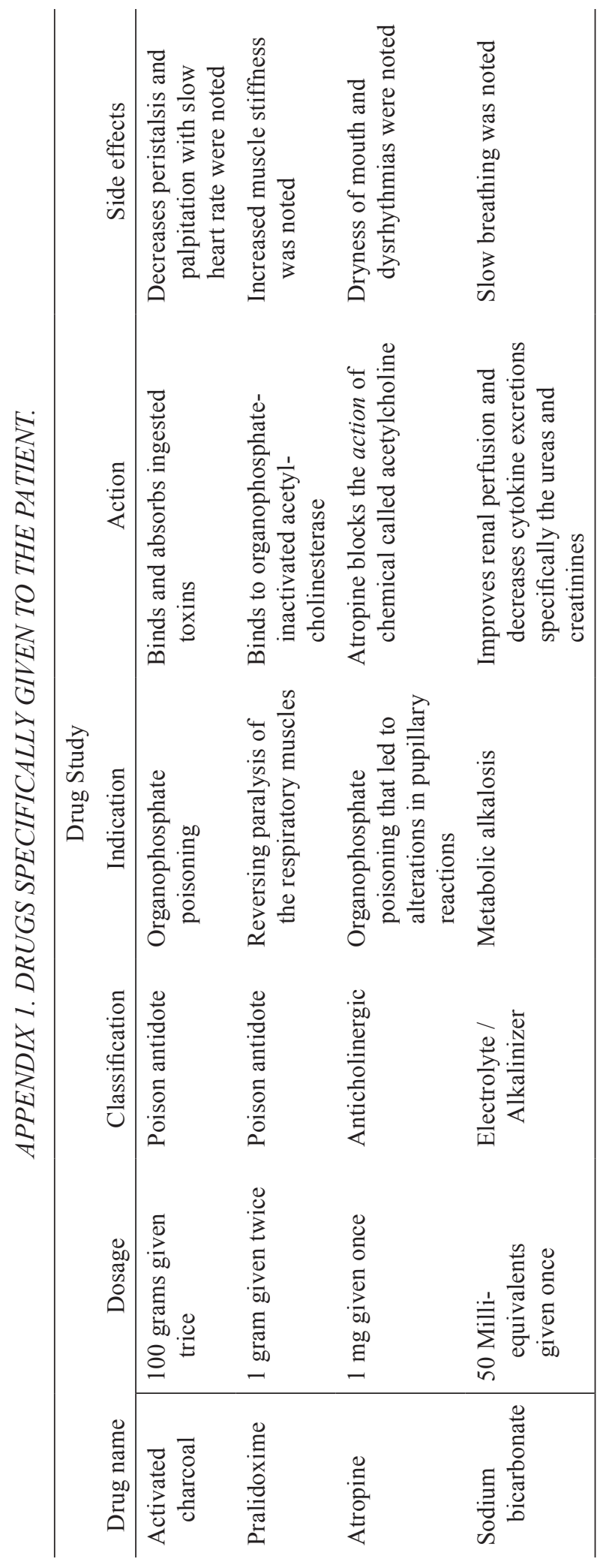

